\title{
Nebulization Therapy With Umbilical Cord Mesenchymal Stem Cell - Derived Exosomes For COVID-19 Pneumonia
}

\author{
Meiping Chu \\ Wuxi Fifth People's Hospital \\ Hao Wang \\ Cruilife Stem Cell co. LTD \\ Linjie Bian \\ The Affiliated Wuxi No. 2 People's Hospital of Nanjing Medical University \\ Jiehui Huang \\ Wuxi Fourth People's Hospital \\ Danping Wu \\ The Affiliated Wuxi No. 2 People's Hospital of Nanjing Medical University \\ Fangli Fei \\ Cruilife Stem Cell co. LTD \\ Ruiting Zhang \\ Cruilife Stem Cell co. LTD \\ Yigang Chen ( $\sim$ wuxichen2512@njmu.edu.cn ) \\ Jiazeng Xia \\ The Affiliated Wuxi No. 2 People's Hospital of Nanjing Medical University
}

The Affiliated Wuxi No.2 People's Hospital of Nanjing Medical University https://orcid.org/0000-0002-3036-3537

Research

Keywords: COVID-19 pneumonia, mesenchymal stem cells, exosomes, nebulization

Posted Date: February 22nd, 2021

DOI: https://doi.org/10.21203/rs.3.rs-99753/v3

License: (c) (i) This work is licensed under a Creative Commons Attribution 4.0 International License. Read Full License 


\section{Abstract}

Background: Scientists have been facing numerous challenges in the development of an effective therapeutic strategy for the treatment of COVID-19 pneumonia. Several studies have suggested that improving patient immunity and reducing lung injury induced by SARS-CoV-2 may be effective for treating patients with COVID-19.

Methods: A pilot trial of nebulization therapy with exosomes of mesenchymal stem cells (MSCs) was performed on seven patients with COVID-19 pneumonia. Exosomes secreted from MSCs were collected and purified using multiple ultrafiltration steps. All patients were treated with nebulization of MSC-derived exosomes, and primary safety and efficacy outcomes were evaluated.

Results: Our clinical study demonstrated that nebulization of MSC-derived exosomes is a novel method that might be utilized in the treatment of COVID-19 pneumonia. Nebulization of MSC-derived exosomes did not induce acute allergic or secondary allergic reactions but did promote the absorption of pulmonary lesions and reduce the time of hospitalization for mild cases of COVID-19 pneumonia.

Conclusions: Nebulization of MSC-derived exosomes is a safe, effective, and simple method, and their application at the beginning of treatment may be more beneficial.

Trial registration: Chinese Clinical Trial Registry, ChiCTR2000030261. Registered on 26 February 2020 - Retrospective registered, http://www.chictr.org.cn

\section{Background}

COVID-19 pneumonia has been declared a global pandemic by the World Health Organization (WHO) and has become a public health emergency [1]. Although the diagnostic efficiency and accuracy of treatment modalities have improved, the overall therapeutic effect remains poor [2]. The major causes of death include severe pneumonia, pulmonary oedema, acute respiratory distress syndrome (ARDS) or multiple organ failure [3].

The two major characteristics of COVID-19 pneumonia are as follows: 1. those with low immunity are more likely to be infected with COVID-19 [4]; and 2. the major target organ is the lung [5]. Indeed, respiratory failure has been reported as one of the major causes of death due to COVID-19 [6], and autopsy has revealed pulmonary injury, significant exudative reaction, and pulmonary embolism in many of these patients [7]. Therefore, COVID-19induced lung injury might be reduced by improving the immunity of patients.

Mesenchymal stem cells (MSCs) have been shown to possess a comprehensive, powerful immunomodulatory function [8, 9]. MSCs can counteract cell death and promote cell regeneration in relation to the pathogenesis of chronic obstructive pulmonary disease, asthma, idiopathic pulmonary fibrosis, acute respiratory distress syndrome, and pulmonary arterial hypertension [10,11]. Moreover, MSC exosomes can both regulate immunity through immune cells and inhibit the inflammatory response through cytokines [12,13]. Numerous studies have demonstrated that exosomes from MSCs may be employed in the treatment of immune deficiency, inflammation, ARDS, and other lung diseases [14, 15]. Therefore, MSC exosomes may also be used in the treatment of COVID-19 pneumonia.

A routine method of stem cell therapy administration is intravenous injection $[16,17]$. Exosomes are one of the major active components secreted by stem cells [18], with sizes ranging from 30-200 nm [19]. Exosomes can reach the bronchioles and alveoli directly after nebulization, which is conducive to maximal drug absorption [15]. Therefore, we hypothesized that nebulized MSC-derived exosomes might be an effective treatment for COVID-19 pneumonia.

\section{Methods}

\section{Study design}

A pilot trial of nebulization therapy for COVID-19 pneumonia with exosomes of MSCs was performed on seven patients with COVID-19 pneumonia. The study was conducted at Wuxi No. 5 People's Hospital, China. The safety and scientific validity of this study have been issued in Chinese Clinical Trial Registry (ChiCTR2000030261).

\section{Inclusion criteria}

We initially enrolled patients with COVID-19 (age 18-65 years) according to the guidance of the National Health and Health Commission of China [20]. We comprehensively considered the patient's epidemiological history, clinical symptoms, and nucleic acid test results. Informed consent was obtained from all patients participating in this clinical study.

\section{Exclusion criteria}

(1) Age < 18 or > 65; (2) severe heart, brain, lung, kidney dysfunction, endocrine disease, haematopoiesis system disease or other serious diseases and psychosis; (3) pregnant and lactating women; (4) participating in other clinical trials or who have participated in other clinical trials in the last 3 months; and (5) unwilling or unable to sign informed consent due to illness. 
The patients were enrolled from February 26, 2020, to April 30, 2020. All enrolled patients were confirmed to have COVID-19 via real-time reverse transcription polymerase chain reaction (RT-PCR) to detect SARS-CoV-2 RNA following the protocol outlined in a previous study [3, 21].

All patients were treated with ritonavir orally, abidol orally, interferon nebulization, or chloroquine phosphate orally (Fig. 1). The clinical, laboratory, and radiological outcomes of all patients were recorded and certified by a trained group of doctors. The detailed records included primary safety data (allergic reactions, secondary infection and life-threatening adverse events) and primary efficacy data (the plasma level of CRP and oxygen saturation). The secondary efficacy outcomes mainly included the total white blood cell count, total lymphocyte count (assessed using a Hitachi 7600-020 automatic biochemical analyser), SARS-CoV-2 nucleic acid detection (assessed by RT-PCR, DAAN GENE Co., Ltd, China), chest CT (assessed using a 320-slice spiral CT scanner, Aquilion One, Toshiba Medical System, Japan), respiratory rate, symptoms (especially fever and shortness of breath), and time of hospitalization. Immune factors were also detected in patient 6 (DxFLEX flow cytometry, BECKMAN, USA).

\section{Umbilical cord processing and cell isolation}

An umbilical cord sample was aseptically collected, and the sample was placed in a collection cup containing medium consisting of DMEM with $4,500 \mathrm{mg} / \mathrm{mL}$ glucose and antibiotic solution containing $0.1 \%$ gentamicin, $0.2 \%$ streptomycin and $0.12 \%$ penicillin. The sample was placed in a foam box precooled to $4^{\circ} \mathrm{C}$ with ice and transported to the laboratory within 4 hours of collection.

The sample in the collection cup was rinsed three times with PBS to remove blood clots and then placed in a Petri dish in a biosafety cabinet. The umbilical cord was cut into 5-cm-long pieces using scissors and forceps. The pieces were cut longitudinally to expose the blood vessels and surrounding Wharton's jelly; the Wharton's Jelly was scraped away from the blood vessels and placed in a separate Petri dish.

The Wharton's jelly was cut into 1-mm pieces with scissors, and $5 \mathrm{ml}$ of each piece was added to a T175 culture flask. Then, $15 \mathrm{~mL}$ of complete medium (Mesenchymal Stem Cell Basal Medium, Cat\# 6114011, Dakewe Bioengineering, China) with 5\% cell culture supplement (EliteGro-Adv. GMP, Cat\# EPAGMP-500, EliteCell Biomedical, Beltsville, MD, USA) and gently shaken so that the tissue pieces were evenly distributed. The sample was incubated at $37^{\circ} \mathrm{C}$ in a $5 \% \mathrm{CO}_{2}$ incubator for 2 days without disturbing the flasks such that the tissue pieces adhered to the flask.

After 5 days of incubation, the medium was changed, and the appearance of the cells outgrowing from the edge of the explant was assessed on a daily basis; cell outgrowth from the adherent explants was often evident after approximately 7 days of culture. Thereafter, the medium was changed every 3 days or as needed. When cell growth reached $70 \%$ confluence, which could be observed at approximately 7 days after the initial cell outgrowth from the explant, subculture of the cells was initiated: the flask was gently shaken so that the tissue pieces dissociated, and they were carefully aspirated together with the supernatant.

The cells remaining in the flask were dissociated by using $4 \mathrm{~mL}$ of commercial trypsin solution per flask and incubated at $37^{\circ} \mathrm{C}$ for two minutes; $5 \mathrm{ml}$ of complete medium was added to neutralize the solution, and the cell suspension was transferred to a centrifuge tube.

The cell suspension was centrifuged at $1,500 \mathrm{x} g$ for six minutes. The pelleted cells were considered passage 0 (P0). For further amplification and characterization, P0 cells were suspended in complete medium, counted, and subcultured at a seeding density of $(1.2-1.4) \times 10^{4} / \mathrm{cm}^{2}$. Excess cells were cryopreserved as P0 cells.

\section{Characterization of isolated cells}

Expression of cell surface markers was analysed using flow cytometry: P5 cells were highly proliferative and positively expressed CD90, CD105, and CD73 but did not express CD34, CD45, CD14, CD19 or HLA-DR. Differentiation potential: P5 cells displayed adipogenic differentiation, chondrogenic differentiation and osteogenic differentiation potentials when cultured in appropriate commercially available differentiation media.

All procedures performed in this study involving human samples were in accordance with the ethical standards of the institutional research committee and the guidelines set by the Declaration of Helsinki.

\section{Isolation and characterization of exosomes isolated from MSCs}

Exosomes secreted from MSCs were collected and purified using multiple ultrafiltration steps (Fig. 2a). The secretions were first centrifuged at $4{ }^{\circ} \mathrm{C}$ at $3000 \mathrm{x} \mathrm{g}$ for $20 \mathrm{~min}$ and filtered through a $0.22 \mu \mathrm{m}$ filter to remove any cells or cell debris. The filtered secretomes were then placed in a new sterile EP tube, followed by the addition of $0.2 \mathrm{ml}$ exosome separation and purification solution (Shanghai Gefan Biotechnology Co., Ltd. Product No.: ex010). The contents were mixed well at $4{ }^{\circ} \mathrm{C}$ overnight and centrifuged at $4{ }^{\circ} \mathrm{C}$ at $3000 \mathrm{xg}$ for 20 min the following day. After the supernatant was aspirated, it was centrifuged at $4{ }^{\circ} \mathrm{C}$ for $1500 \mathrm{xg}$ for $5 \mathrm{~min}$ to remove the residual solution. After adding $1000 \mu$ sterile PBS to resuspend and precipitate the exosomes, the solution was centrifuged for 1 hour at $100000 \mathrm{xg}$ using a high-speed centrifuge, and this was repeated three times. The exosome samples were analysed for proper size using nanoparticle tracking analysis (NTA; NanoSight NS300, Malvern) and for morphology using transmission electron microscopy (TEM; Tecnai G2 Spirit Bio TWIN). Additionally, successful exosome isolation was confirmed using immunoblotting for known exosome markers. Standard Western blotting was performed using rabbit antibodies against human CD9 (1:2000, ab92726, Abcam), CD81 
(1:6000, ab109201, Abcam), and Flotillin 2 (1:6000, ab181988, Abcam). Protein sample loading was monitored by probing the same membrane filter with an anti- $\beta$-actin antibody (1:2000, sc-130301, Santa Cruz) (Fig. 2).

After nebulization, the MSC exosomes were sprayed onto a sterile glass plate, and a dish was placed under the glass plate for collecting the liquid containing the exosomes. After nebulization, the size and markers of the MSC exosomes were evaluated again. No significant difference in the size and markers of MSC-derived exosomes before and after nebulization was observed (Fig. $2 \mathrm{c}$ and d).

\section{Nebulization of MSC-derived exosomes}

After obtaining ethical approval, all patients diagnosed with COVID-19 pneumonia who provided informed consent were treated with nebulization of MSC-derived exosomes. All patients were treated with the same dose of MSCs ( 1 million cells/kg predicted body weight) according to a previous study [22]. The concentration of exosomes for nebulization for each patient ranged from $7.66 \mathrm{e}+0.8$ to $7.00 \mathrm{e}+0.7 \mathrm{particles} / \mathrm{ml}$ based on $\mathrm{NanoSight}$. The exosomes extracted from MSCs were diluted to $5 \mathrm{ml}$ with $0.9 \%$ sodium chloride and added to an atomizer (Emedical, Excellentcare Medical Ltd. China). Nebulization was performed twice a day (am 8:30, pm 16:00) for 10 minutes each. The patients were assessed by investigators after receiving the nebulization treatment.

\section{Treatment procedure for MSC-derived exosomes and general patient information}

This study was conducted from February 26, 2020, to September 4, 2020. Seven patients diagnosed with COVID-19 pneumonia, including 2 severe cases (patients 2 and 4) and 5 mild cases (patients 1, 3, 5, 6 and 7), were enrolled in the study (Table 1). Patients 1, 2, 3 and 4 received nebulization of MSC-derived exosomes after antiviral treatment for a period of time. Patient 1 had a mild case of COVID-19 and did not have any underlying disease conditions. Patient 2 had a severe case of COVID-19 and liver damage. Patient 3 was a mild case and patient 4 a severe case, both without any underlying disease. Patients 5, 6 and 7 received nebulization of MSC-derived exosomes from the beginning of treatment. Information about all the treatment modalities of the patients was collected. The timepoint of the delivery of MSC-derived exosome nebulization treatment for each patient is shown in Fig 1.

Table 1. General information of the enrolled patients.

\begin{tabular}{|c|c|c|c|c|c|c|c|}
\hline & Patient 1 & Patient 2 & Patient 3 & Patient 4 & Patient 5 & Patient 6 & Patient 7 \\
\hline Age (years) & 62 & 53 & 23 & 61 & 43 & 19 & 57 \\
\hline Underlying diseases & No & Liver damage & No & No & Fatty liver & No & Diabetes mellitus \\
\hline COVID-19 type & Common & Severe & Common & Severe & Common & Common & Common \\
\hline Cough & Yes & Yes & No & Yes & No & No & Yes \\
\hline Weak & Yes & No & No & Yes & No & No & No \\
\hline Diarrhoea & No & Yes & No & No & No & No & No \\
\hline Shortness of breath & No & No & No & Yes & No & No & No \\
\hline Date of diagnosed & Feb 9 & Feb 9 & Feb 8 & Jan 31 & Mar 28 & Mar 27 & Aug 20 \\
\hline Date of MSCs exosomes treatment & Feb 27 & Feb 27 & Feb 27 & Feb 27 & Apr 1 & Apr 4 & Aug 23 \\
\hline Date of recovery & Mar 2 & Mar 2 & Mar 11 & Mar 9 & Apr 11 & Apr 13 & Sep 4 \\
\hline Hospital day & 22 & 22 & 31 & 38 & 14 & 17 & 15 \\
\hline
\end{tabular}

Yes: Presence of relevant clinical symptoms, such as cough, weak, diarrhoea, shortness of breath and chest tightness.

No: No relevant clinical symptoms.

\section{Statistical analysis}

Data that were suitable for statistical analysis were analysed using SPSS software (SPSS 22.0). Differences between two groups were assessed using unpaired two-tailed $t$ tests or chi square tests based on the type of data. Data involving more than two groups were assessed using analysis of variance (ANOVA). $P$ values $<0.05$ indicated statistical significance. 


\section{Results}

\section{The primary safety outcome}

No acute allergic reactions, such as itchy rash, swelling of the throat or tongue, shortness of breath, vomiting, lightheadedness, or low blood pressure, were observed within two hours after the nebulization treatment. Secondary allergic reactions were also not observed posttreatment. No adverse events were reported.

MSC therapy is considered safe for lung diseases, such as chronic obstructive pulmonary disease (COPD), acute respiratory distress syndrome (ARDS), and idiopathic pulmonary fibrosis (IPF) [23, 24]. Numerous completed phase I trials have reported no serious, acute, or adverse events for MSC therapy $[22,25]$. Several studies have been conducted on the safety of MSC exosome therapy. The findings of these studies suggest that MSCderived exosomes can be safely and easily used in the treatment of lung diseases [26]. However, the route of administration of MSC-derived exosomes in most studies was through intravenous injection. Our results demonstrated that nebulization of MSC-derived exosomes is safe and may be employed in the treatment of lung diseases.

\section{The efficacy outcome}

Plasma C-reactive protein (CRP) levels decreased from $88.4 \mathrm{mg} / \mathrm{L}$ (Feb 17) to $4.3 \mathrm{mg} / \mathrm{L}$ (Feb 28) and $0.4 \mathrm{mg} / \mathrm{L}$ (Mar 1) in patient 1. In patient 2 (severe type), CRP decreased from $30.8 \mathrm{mg} / \mathrm{L}$ (Feb 23) to $18.9 \mathrm{mg} / \mathrm{L}$ (Feb 28) and $3.5 \mathrm{mg} / \mathrm{L}$ (Mar 2); in patient 3, it decreased from $5.7 \mathrm{mg} / \mathrm{L}$ (Feb 15 ) to 0.5 $\mathrm{mg} / \mathrm{L}$ (Mar 3). CRP decreased from $31.8 \mathrm{mg} / \mathrm{L}$ (Feb 25) to $11.4 \mathrm{mg} / \mathrm{L}$ (Mar 9) in patient 4 (severe type). The nebulization treatment in patients 1, 2, 3, and 4 started on February 27. For patient 5, CRP levels were $0.5 \mathrm{mg} / \mathrm{L}$ (Mar 28) and $0.5 \mathrm{mg} / \mathrm{L}$ (April 4), without any change. However, CRP levels decreased from $2.2 \mathrm{mg} / \mathrm{L}$ (March 30) to $0.5 \mathrm{mg} / \mathrm{L}$ (April 8) in patient 6 . The nebulization treatment for patients 5 and 6 started on April 1 and April 4 , respectively. In patient 7, CRP levels were $1.9 \mathrm{mg} / \mathrm{L}$ (August 19), $5.4 \mathrm{mg} / \mathrm{L}$ (August 25) and $3 \mathrm{mg} / \mathrm{L}$ (August 29) (Table 2). The nebulization treatment for patients 5 and 7 started on April 1 and August 20. Although the CRP value before the nebulization treatment (23.00 \pm 31.87$)$ was comparatively higher than that after treatment $(3.17 \pm 4.12)$, there was no significant difference between the two values $(p=0.151)$.

Table 2. Efficacy outcomes before and after nebulization treatment.

\begin{tabular}{|c|c|c|c|c|c|c|c|c|c|c|c|c|c|c|c|}
\hline \multirow[t]{2}{*}{$\begin{array}{l}\text { Laboratory } \\
\text { index }\end{array}$} & \multicolumn{2}{|c|}{$\begin{array}{l}\text { Patient } 1 \\
\text { (common } \\
\text { type) }\end{array}$} & $\begin{array}{l}\text { Patient } 2 \\
\text { (severe type) }\end{array}$ & \multicolumn{2}{|c|}{$\begin{array}{l}\text { Patient } 3 \\
\text { (common } \\
\text { type) }\end{array}$} & \multicolumn{3}{|c|}{$\begin{array}{l}\text { Patient } 4 \\
\text { (severe type) }\end{array}$} & \multicolumn{2}{|c|}{$\begin{array}{l}\text { Patient } 5 \\
\text { (common } \\
\text { type) }\end{array}$} & \multicolumn{2}{|c|}{$\begin{array}{l}\text { Patient } 6 \\
\text { (common } \\
\text { type) }\end{array}$} & \multicolumn{2}{|c|}{$\begin{array}{l}\text { Patient } 7 \\
\text { (common } \\
\text { type) }\end{array}$} & \multirow[t]{2}{*}{$\begin{array}{l}P \\
\text { value }\end{array}$} \\
\hline & Before & After & Before & After & Before & After & Before & After & Before & After & Before & After & Before & After & \\
\hline $\begin{array}{l}\text { C-reactive } \\
\text { protein } \\
\text { (mg/L) }\end{array}$ & 88.4 & 0.4 & 30.8 & 3.5 & 5.7 & 0.5 & 31.8 & 11.4 & 0.5 & 0.5 & 2.2 & 0.5 & 1.9 & 5.4 & 0.151 \\
\hline $\begin{array}{l}\text { White cell } \\
\text { count } \\
\left({ }^{*} 10^{9} \text { per }\right. \\
\text { litre })\end{array}$ & 5.28 & 4.96 & 5.99 & 5.02 & 7.28 & 6.87 & 6.38 & 3.95 & 8.16 & 5.26 & 6.02 & 8.41 & 4.34 & 5.63 & 0.479 \\
\hline $\begin{array}{l}\text { Lymphoma } \\
\text { count } \\
\left({ }^{\star} 10^{9} \text { per }\right. \\
\text { litre) }\end{array}$ & 3.6 & 2.91 & 1.36 & 2.03 & 2.87 & 2.62 & 1.17 & 1.1 & 2.77 & 2.36 & 2.08 & 2.08 & 3.08 & 2.95 & 0.770 \\
\hline $\begin{array}{l}\text { Respiratory } \\
\text { rate }(/ \mathrm{min})\end{array}$ & 12 & 13 & 32 & 25 & 15 & 14 & 22 & 20 & 14 & 15 & 16 & 15 & 13 & 14 & 0.723 \\
\hline Fever $\left({ }^{\circ} \mathrm{C}\right)$ & 36.5 & 36.6 & 36.7 & 36.5 & 36.3 & 36.4 & 37.1 & 37 & 36.5 & 36.6 & 36.4 & 36.5 & 37.6 & 36.5 & 0.468 \\
\hline $\begin{array}{l}\text { Shortness } \\
\text { of breath }\end{array}$ & No & No & Yes & No & No & No & No & No & No & No & No & No & No & No & \\
\hline
\end{tabular}

Before: Before nebulization treatment.

After: After nebulization treatment.

No: No shortness of breath.

Yes: Shortness of breath.

In patient 1, oxygen saturation without supplementation rose from 95\% (Feb 26) to 98 \% (Mar 2), and it increased from 95\% (Feb 26) to $98 \%$ (Mar 3) in patient 2 (severe type). Oxygen saturation rose from 95\% (Feb 26) to $100 \%$ (Mar 1) in patient 4 (severe type), but there was no significant change in oxygen saturation in patients 3, 5, 6 and 7 after the nebulization treatment. Therefore, we observed no significant difference in oxygen saturation before and after nebulization of MSC exosomes ( $p \llbracket 0.05)$. 
Additionally there was no significant difference in the total white blood cell count, total lymphocyte count, fever or shortness of breath before and after the nebulization treatment ( $p \llbracket 0.05)$. Alanine aminotransferase (ALT) in patient 2 , which was a severe case with liver function damage, decreased from $168 \mu / \mathrm{I}$ (Feb 26) to $92 \mu / \mathrm{l}$ (Feb 28) and $52 \mu / \mathrm{l}$ (Mar 2).

Computed tomography (CT) of the chest revealed that the nebulization of MSC-derived exosomes was beneficial in promoting the absorption of pulmonary lesions. On April 3, the first CT scan of patient 6 (mild case of COVID-19 pneumonia receiving nebulization of MSC-derived exosomes from April 4) showed an isolated nodule outside the left lower lobe of the lung. On April 10, the second CT examination showed that the density of the left inferior lobe nodule was significantly lower, with a narrow range. On April 21, the third CT examination showed that the lesions in the lower left lung had absorbed completely. The time required for complete absorption of pulmonary lesions in patient 6 was 18 days. Comparatively, the absorption time of similar lung lesions in another patient (a mild case of COVID-19 pneumonia not receiving nebulization treatment) was 27 days. Indeed, there was a significant difference in the time of complete absorption of pulmonary lesions $(16.00 \pm 5.23$ vs $20.85 \pm 3.57)$ between patients who received nebulization of exosomes from the beginning of treatment and other patients (not receiving nebulization or receiving it at the end of treatment) with mild cases of COVID-19 pneumonia ( $p=0.033)$. Patients with severe cases of COVID-19 pneumonia received nebulization treatment at the later stage of treatment. Compared to those who did not receive nebulization treatment, patient 2 showed obvious absorption of pulmonary lesions. In addition, fibrous shadows were present in the lung lesions of patients who did not receive nebulization treatment (Fig. 3). CT images of the other five patients are shown in Fig. 4.

Several studies have demonstrated that bone marrow-derived exosomes can reduce lung inflammation and alleviate pulmonary oedema and postinflammatory complications in animal models of acute lung injury, ARDS, asthma and other inflammatory diseases [27-29]. MSC-derived exosomes usually contain bioactive substances such as mRNA, miRNA and protein [30,31], and these substances have been shown to effectively reduce inflammatory processes and modulate airway remodelling [15, 32]. We also demonstrated that MSC-derived exosomes can reduce the CRP level in patients with different degrees of COVID-19 pneumonia, similar to the findings of a previous study [20].

Despite the observed decrease in CRP after the nebulization treatment, it did not achieve statistical significance due to the small number of cases and large standard deviation. Nevertheless, the patients who received nebulization treatment at an earlier stage experienced more beneficial effects in terms of pulmonary lesion absorption. Our results showed that nebulization of MSC-derived exosomes is beneficial for the absorption of pulmonary lesions in mild cases of COVID-19 pneumonia and in reducing cellular residue in severe cases.

\section{Time of hospitalization}

The average time of hospitalization was $18.74 \pm 4.72$ days for all COVID-19 patients, $18.29 \pm 4.60$ days for mild cases, and $22.6 \pm 4.3$ days for severe cases. The time of hospitalization for patients 5, 6 and 7, with mild cases of COVID-19 (who received nebulization of exosomes from the beginning of treatment), was $15.3 \pm 1.33$ days (14, 17 and 15 days, respectively). The time of hospitalization for patients 1 and 3 , with mild cases of COVID-19 (who received nebulization of exosomes at the end of treatment), was 22 and 31 days, respectively. There was a significant difference in the time of hospitalization between the patients who received nebulization of exosomes from the beginning of treatment and other patients (not receiving nebulization or receiving nebulization at the end of treatment) with mild cases of COVID-19 pneumonia $(p=0.035)$. The time of hospitalization for patients 2 and 4 with severe cases of COVID-19 (who received nebulization of exosomes at the end of treatment) was 22 and 38 days, respectively. Those who received nebulization treatment at an earlier stage showed more beneficial effects in terms of hospitalization stay.

\section{COVID-19 nucleic acid detection}

RT-PCR was performed using the genomic DNA of patients with COVID-19 pneumonia. In all patients, nucleic acid positivity became negative before exosome nebulization.

\section{Serum immune factor analysis}

Patient 6 was tested for immune factors (IL-2, IL-4, IL-6, IL-10, TNFa, IFN- $\gamma$, IL-17A, CD3, CD4, CD8, CD4/CD8, TH19 and NK), and the largest difference post nebulization treatment was observed for IFN- - . TWe detected a twofold increase in IFN- $\gamma$, IL-17A and TH19 after nebulization treatment, whereas NK cells showed a twofold decrease after treatment (Table 3 ).

Table 3. Analysis of serum immune factors in patient 6. Nebulization was performed on April 4. 


\begin{tabular}{|c|c|c|c|c|c|c|c|c|c|c|c|c|c|}
\hline Date & $\begin{array}{l}\text { IL-2 } \\
(\mathrm{pg} / \mathrm{ml})\end{array}$ & $\begin{array}{l}\text { IL-4 } \\
(\mathrm{pg} / \mathrm{ml})\end{array}$ & $\begin{array}{l}\text { IL-6 } \\
(\mathrm{pg} / \mathrm{ml})\end{array}$ & $\begin{array}{l}\text { IL-10 } \\
(\mathrm{pg} / \mathrm{ml})\end{array}$ & $\begin{array}{l}\text { TNF-a } \\
(\mathrm{pg} / \mathrm{ml})\end{array}$ & $\begin{array}{l}\text { IFN-y } \\
(\mathrm{pg} / \mathrm{ml})\end{array}$ & $\begin{array}{l}\text { IL-17A } \\
(\mathrm{pg} / \mathrm{ml})\end{array}$ & $\begin{array}{l}\text { CD3 } \\
(\%)\end{array}$ & $\begin{array}{l}\text { CD4 } \\
(\%)\end{array}$ & $\begin{array}{l}\text { CD8 } \\
(\%)\end{array}$ & CD4/CD8 & $\begin{array}{l}\text { TH19 } \\
(\%)\end{array}$ & $\begin{array}{l}\text { NK } \\
\text { (\%) }\end{array}$ \\
\hline $\begin{array}{l}\text { Before } \\
\text { (March } \\
30 \text { ) }\end{array}$ & 2.19 & 2.05 & 3.25 & 2.76 & 1.94 & 0.63 & 0 & 55.5 & 25.88 & 23.13 & 1.12 & 7.56 & 31.04 \\
\hline $\begin{array}{l}\text { After } \\
\text { (April } \\
8)\end{array}$ & No & No & 3.54 & 0.83 & No & No & No & 67.62 & 33.52 & 27.64 & 1.21 & 14.40 & 14.68 \\
\hline $\begin{array}{l}\text { After } \\
\text { (April } \\
13)\end{array}$ & 0.51 & 3.65 & 4.57 & 2.13 & 1.01 & 41.23 & 4.73 & 64.91 & 33.98 & 25.72 & 1.35 & 15.15 & 15.20 \\
\hline
\end{tabular}

Before: Before nebulization treatment.

After: After nebulization treatment.

No: No data.

IFN-y is an important target of immunotherapy. Several studies have shown that it is closely related to the disease severity, treatment effect and prognosis of COVID-19 pneumonia [33,34]. Utilizing the potential therapeutic effect of IFN to manage COVID-19-induced cytokine release syndrome should be considered for clinical application [35]. In this study, levels of IFN-y increased obviously after exosome nebulization. However, more cases are needed to confirm this effect.

Although several therapeutic approaches have been proposed for COVID-19 pneumonia, only a few of them are effective. At present, it is believed that reducing lung injury may be the key to saving these patients. Our results suggest that nebulization of MSC-derived exosomes can promote the absorption of pulmonary lesions and reduce the time of hospitalization for mild cases of COVID-19 pneumonia. In addition, nebulization of MSCderived exosomes from the beginning of the treatment may be more beneficial to patients.

In general, drug nebulization is an effective way to treat lung diseases, and nebulized exosomes can act directly on the lungs, with a faster effect. However, there are only a few reports on the nebulization of MSC-derived exosomes to date. Our results indicate that nebulization of MSC-derived exosomes is a safe and feasible therapeutic approach for the treatment of patients with COVID-19 pneumonia. After the extraction of exosomes, they can be stored up to a week at $4^{\circ} \mathrm{C}$ and may be added to an existing atomizer when required. The convenience of drug storage and its use is crucial for COVID-19 pneumonia therapy, especially in countries and regions lacking advanced health-care facilities.

Our research has obvious limitations. Due to the short duration of the outbreak in China, only seven COVID-19 pneumonia patients were included in this study. Additionally, only 3 patients underwent nebulization of MSC-derived exosomes from the beginning of treatment. It should also be noted that we did not compare exosome nebulization treatment to various other administration methods, such as intravenous injection.

\section{Conclusion}

In conclusion, nebulization of MSC exosomes is a novel method that may be used in the treatment of COVID-19 pneumonia. Our clinical study involving a small sample size shows that this method is safe, effective and simple, especially for mild cases of COVID-19 pneumonia. Nebulization of MSC-derived exosomes from the beginning of the treatment may benefit patients more effectively.

\section{Abbreviations}

Acute respiratory distress syndrome (ARDS)

World Health Organization (WHO)

Mesenchymal stem cells (MSCs)

\section{Declarations}

\section{Ethics approval and consent to participate}

The study was conducted in Wuxi No.5 people's Hospital, China, and approved by the ethics committee of the hospital (No. 2020- 003-1). The safety and scientific validity of this study "have been issued in Chinese Clinical Trial Registry (ChiCTR2000030261). 
Clinical data from patients were obtained after acquiring consent of patients in accordance with the protocol approved by the Ethics Committee of the ethics committee of Wuxi No.5 people's Hospital, China.

\section{Consent for publication}

All presentations of case reports have consent for publication.

\section{Availability of data and materials}

All supporting data are included in the article.

\section{Competing interests}

The authors declare that they have no conflicts of interest related to the studies described.

\section{Funding}

This work was supported by COVID-19 infection emergency control project of Wuxi science and Technology Bureau (N2020x008). The funding body play an important role in collecting, analyzing and interpreting data and writing manuscripts.

\section{Authors' contributions}

Conceptualization, Yigang Chen and Hao Wang; Methodology, Chu mei-ping, Hao Wang, Fangli Fei and Ruiting Zhang; Software, Linjie Bian; Formal Analysis, Danping Wu and Linjie Bian; Investigation, Chu mei-ping and Huang jie-hui; Resources, Chu mei-ping and Huang jie-hui; Writing - Original Draft, Yigang Chen; Writing - Review \& Editing, Hao Wang, Supervision, Jiazeng Xia; Project Administration, Jiazeng Xia; Funding Acquisition, Yigang Chen and Chu mei-ping. All authors read and approved the final manuscript.

\section{Acknowledgements}

We thank the Springer Nature Author Services for their professional writing services.

\section{References}

1. Rubin EJ, Baden LR, Morrissey S. Audio interview: studying potential Covid-19 Therapies. N Engl J Med. 2020;382:e72.

2. Wang C, Horby PW, Hayden FG, Gao GF. A novel coronavirus outbreak of global health concern. Lancet. 2020;395:470-3.

3. Huang C, Wang Y, Li X, Ren L, Zhao J, Hu Y, et al. Clinical features of patients infected with 2019 novel coronavirus in Wuhan, China. Lancet. 2020;395:497-506.

4. Banerjee A, Pasea L, Harris S, Gonzalez-Izquierdo A, Torralbo A, Shallcross L, et al. Estimating excess 1-year mortality associated with the COVID19 pandemic according to underlying conditions and age: a population-based cohort study. Lancet. 2020;395:1715-25.

5. Rubin R. Global effort to collect data on ventilated patients with COVID-19. JAMA. 2020;323:2233-4.

6. Liang W, Liang H, Ou L, Chen B, Chen A, Li C, et al. Development and validation of a clinical risk score to predict the occurrence of critical illness in hospitalized patients with COVID-19. JAMA Intern Med. 2020;180:1081-9.

7. Wichmann D, Sperhake JP, Lütgehetmann M, Steurer S, Edler C, Heinemann A, et al. Autopsy findings and venous thromboembolism in patients with COVID-19: a prospective cohort study. Ann Intern Med. 2020;173:268-77.

8. Carrade Holt DD, Wood JA, Granick JL, Walker NJ, Clark KC, Borjesson DL. Equine mesenchymal stem cells inhibit T cell proliferation through different mechanisms depending on tissue source. Stem Cells Dev. 2014;23:1258-65.

9. Jia XH, Feng GW, Wang ZL, Du Y, Shen C, Hui H, et al. Activation of mesenchymal stem cells by macrophages promotes tumor progression through immune suppressive effects. Oncotarget. 2016;7:20934-44.

10. Sauler M, Bazan IS, Lee PJ. Cell death in the lung: the apoptosis-necroptosis axis. Annu Rev Physiol. 2019;81:375-402.

11. Naji A, Suganuma N, Espagnolle N, Yagyu KI, Baba N, Sensebé L, et al. Rationale for determining the functional potency of mesenchymal stem cells in preventing regulated cell death for therapeutic use. Stem Cells Transl Med. 2017;6:713-9.

12. Yang C, Lim W, Park J, Park S, You S, Song G. Anti-inflammatory effects of mesenchymal stem cell-derived exosomal microRNA-146a-5p and microRNA-548e-5p on human trophoblast cells. Mol Hum Reprod. 2019;25:755-71.

13. Kojima M, Gimenes-Junior JA, Chan TW, Eliceiri BP, Baird A, Costantini TW, et al. Exosomes in postshock mesenteric lymph are key mediators of acute lung injury triggering the macrophage activation via Toll-like receptor 4. Faseb j. 2018;32:97-110.

14. Abraham A, Krasnodembskaya A. Mesenchymal stem cell-derived extracellular vesicles for the treatment of acute respiratory distress syndrome. Stem Cells Transl Med. 2020;9:28-38.

15. Fujita Y, Kadota T, Araya J, Ochiya T, Kuwano K. Clinical application of mesenchymal stem cell-derived extracellular vesicle-based therapeutics for inflammatory lung diseases. J Clin Med. 2018;7:355. 
16. Park WB, Kim SY, Lee SH, Kim HW, Park JS, Hyun JK. The effect of mesenchymal stem cell transplantation on the recovery of bladder and hindlimb function after spinal cord contusion in rats. BMC Neurosci. 2010;11:119.

17. Trounson A, Thakar RG, Lomax G, Gibbons D. Clinical trials for stem cell therapies. BMC Med. 2011;9:52.

18. Sharma A. Role of stem cell derived exosomes in tumor biology. Int J Cancer. 2018;142:1086-92.

19. Shin S, Han D, Park MC, Mun JY, Choi J, Chun H, et al. Separation of extracellular nanovesicles and apoptotic bodies from cancer cell culture broth using tunable microfluidic systems. Sci Rep. 2017;7:9907.

20. Leng Z, Zhu R, Hou W, Feng Y, Yang Y, Han Q, et al. Transplantation of ACE2(-) mesenchymal stem cells improves the outcome of patients with COVID-19 Pneumonia. Aging Dis. 2020;11:216-28.

21. Wang D, Hu B, Hu C, Zhu F, Liu X, Zhang J, et al. Clinical characteristics of 138 hospitalized patients with 2019 novel coronavirus-infected pneumonia in Wuhan, China. JAMA. 2020;323:1061-9.

22. Wilson JG, Liu KD, Zhuo H, Caballero L, McMillan M, Fang X, et al. Mesenchymal stem (stromal) cells for treatment of ARDS: a phase 1 clinical trial. Lancet Respir Med. 2015;3:24-32.

23. Stolk J, Broekman W, Mauad T, Zwaginga JJ, Roelofs H, Fibbe WE, et al. A phase I study for intravenous autologous mesenchymal stromal cell administration to patients with severe emphysema. QJM. 2016;109:331-6.

24. Tzouvelekis A, Paspaliaris V, Koliakos G, Ntolios P, Bouros E, Oikonomou A, et al. A prospective, non-randomized, no placebo-controlled, phase Ib clinical trial to study the safety of the adipose derived stromal cells-stromal vascular fraction in idiopathic pulmonary fibrosis. $\mathrm{J}$ Transl Med. 2013;11:171.

25. Chambers DC, Enever D, llic N, Sparks L, Whitelaw K, Ayres J, et al. A phase $1 \mathrm{~b}$ study of placenta-derived mesenchymal stromal cells in patients with idiopathic pulmonary fibrosis. Respirology. 2014;19:1013-8.

26. Breitbach M, Bostani T, Roell W, Xia Y, Dewald O, Nygren JM, et al. Potential risks of bone marrow cell transplantation into infarcted hearts. Blood. 2007;110:1362-9.

27. Lee JH, Park J, Lee JW. Therapeutic use of mesenchymal stem cell-derived extracellular vesicles in acute lung injury. Transfusion. 2019;59:87683.

28. Wang M, Yuan Q, Xie L. Mesenchymal stem cell-based immunomodulation: properties and clinical application. Stem Cells Int. 2018;2018:3057624.

29. Weiss DJ, Casaburi R, Flannery R, LeRoux-Williams M, Tashkin DP. A placebo-controlled, randomized trial of mesenchymal stem cells in COPD. Chest. 2013;143:1590-8.

30. Marote A, Teixeira FG, Mendes-Pinheiro B, Salgado AJ. MSCs-derived exosomes: cell-secreted nanovesicles with regenerative potential. Front Pharmacol. 2016;7:231

31. Théry C, Witwer KW, Aikawa E, Alcaraz MJ, Anderson JD, Andriantsitohaina R, et al. Minimal information for studies of extracellular vesicles 2018 (MISEV2018): a position statement of the International Society for Extracellular Vesicles and update of the MISEV2014 guidelines. J Extracell Vesicles. 2018;7:1535750.

32. de Castro LL, Xisto DG, Kitoko JZ, Cruz FF, Olsen PC, Redondo PAG, et al. Human adipose tissue mesenchymal stromal cells and their extracellular vesicles act differentially on lung mechanics and inflammation in experimental allergic asthma. Stem Cell Res Ther. $2017 ; 8: 151$.

33. Gadotti AC, de Castro Deus M, Telles JP, Wind R, Goes M, Garcia Charello Ossoski R, et al. IFN- $\gamma$ is an independent risk factor associated with mortality in patients with moderate and severe COVID-19 infection. Virus Res. 2020;289:198171.

34. Zhang F, Mears JR, Shakib L, Beynor JI, Shanaj S, Korsunsky I, et al. IFN- y and TNF- a drive a CXCL10 + CCL2 + macrophage phenotype expanded in severe COVID-19 and other diseases with tissue inflammation. bioRxiv. 2020; doi: 10.1101/2020.08.05.238360.

35. Ghazavi A, Ganji A, Keshavarzian N, Rabiemajd S, Mosayebi G. Cytokine profile and disease severity in patients with COVID-19. Cytokine. 2021;137:155323.

\section{Figures}




\section{7 enrolled patients}
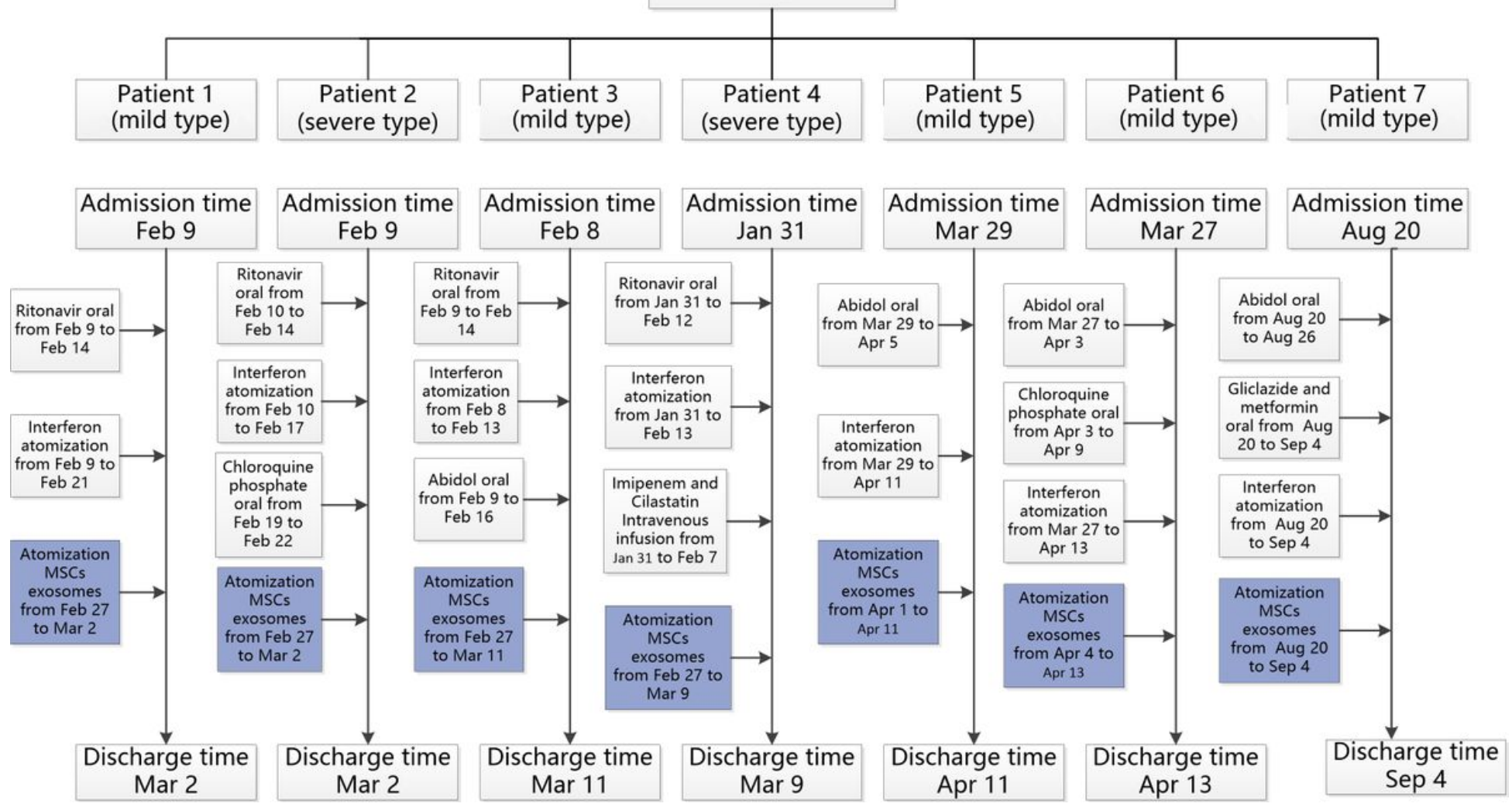

Figure 1

Flow chart showing the timeline of MSC-derived exosome nebulization treatment. 

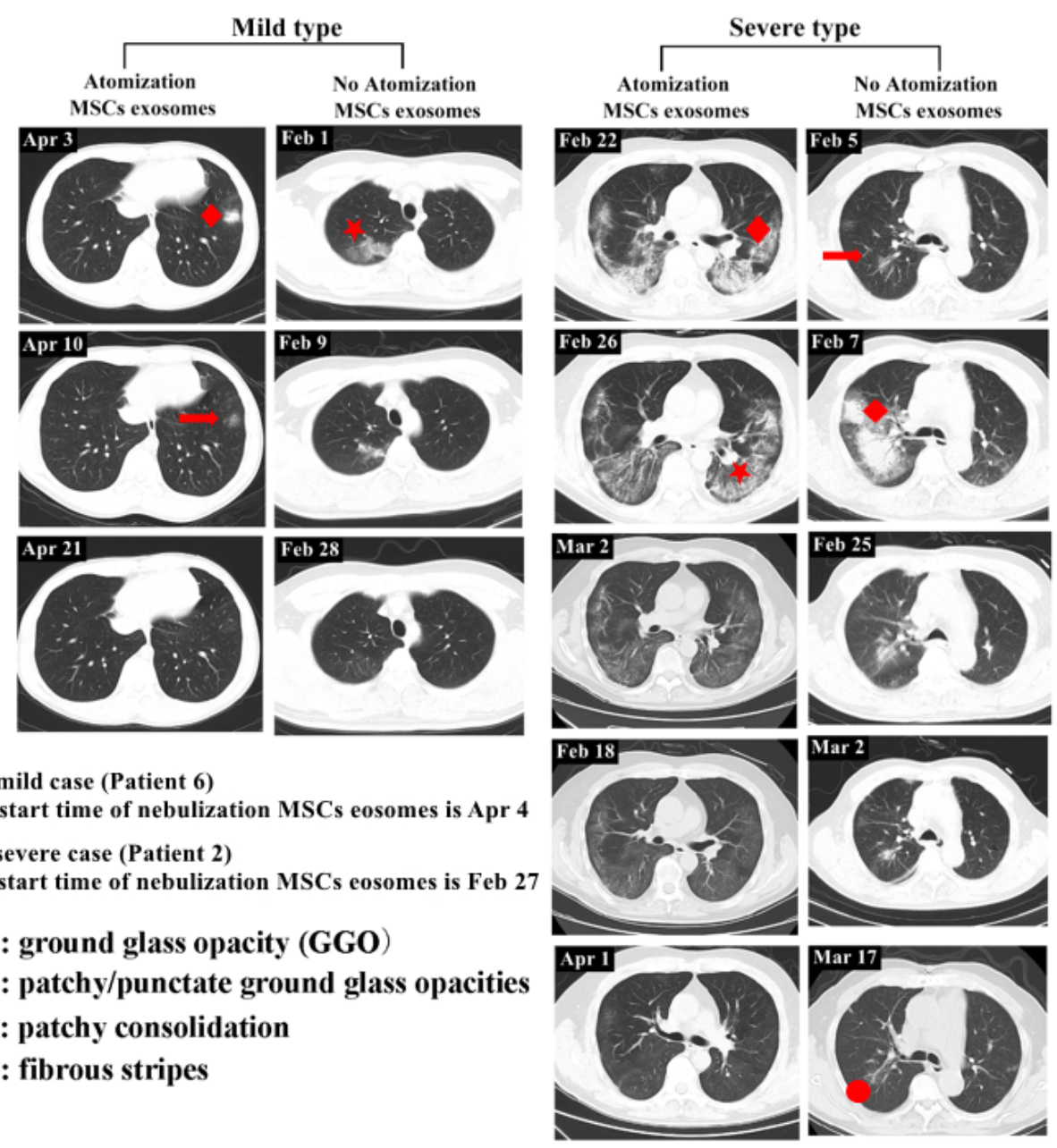

Figure 2

Isolation and characterization of exosomes from MSCs. (a) Schematic diagram of nebulization treatment of MSC-derived exosome exosomes. (b) Schematic diagram of the exosome collecting device after atomization. (c) Exosome samples were analysed by nanoparticle tracking analysis and transmission electron microscopy. (d) Exosome samples were confirmed by immunoblotting for the known exosome markers CD9, CD81 and Flotillin 2 . 

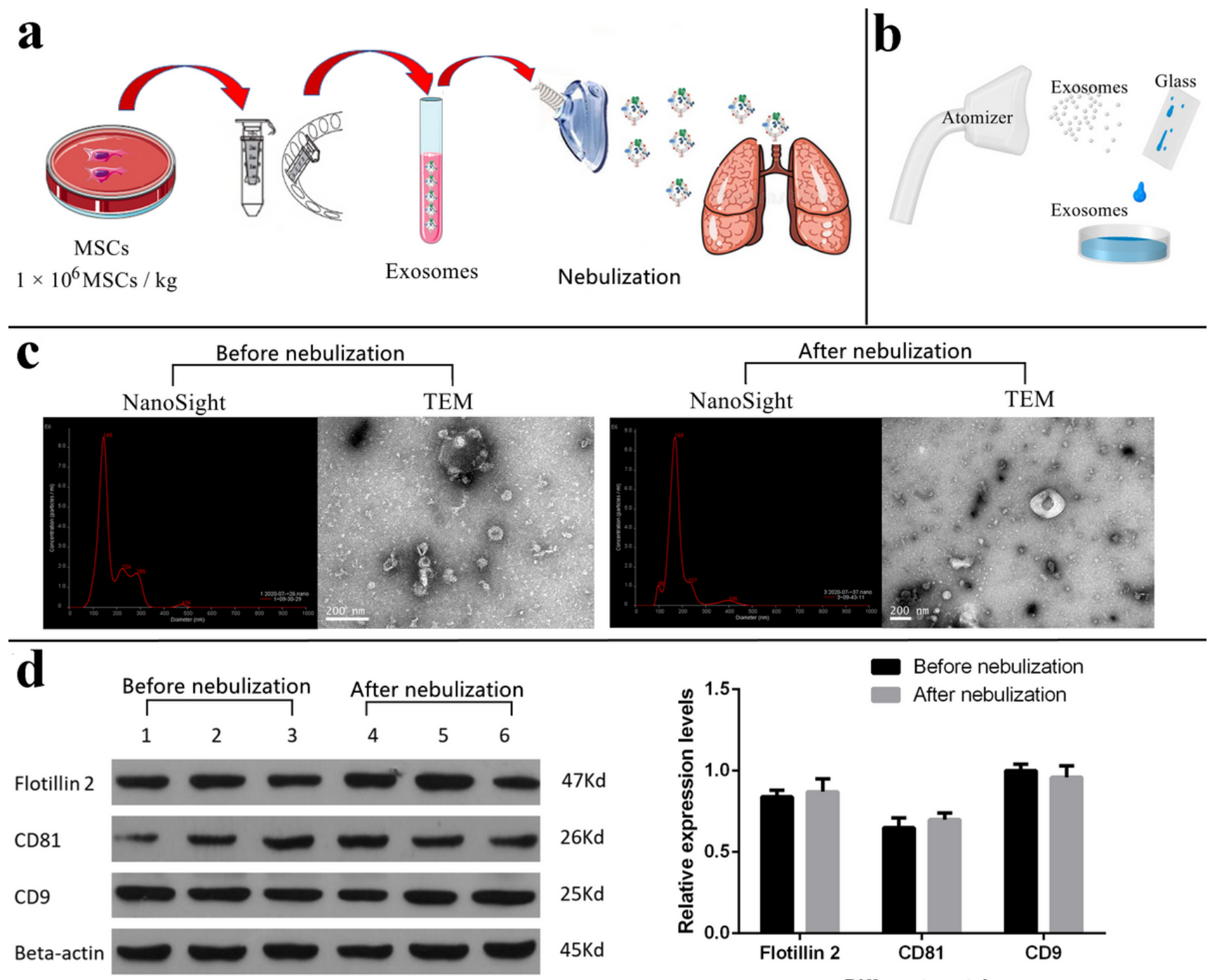

$47 K d$

$26 K d$

$25 \mathrm{Kd}$

$45 \mathrm{Kd}$

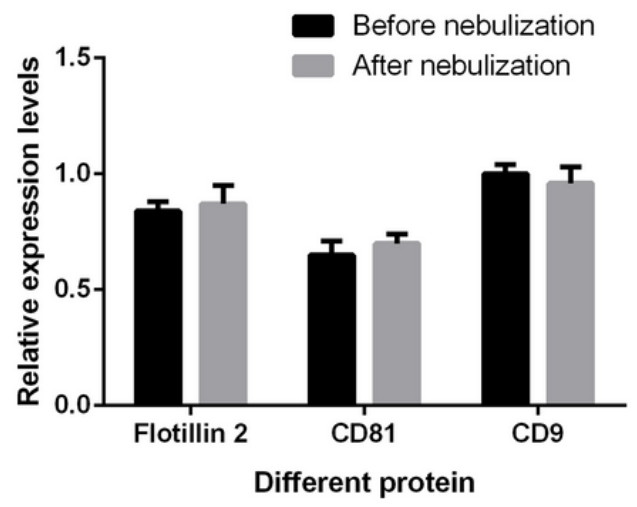

Figure 3

Chest computed tomography (CT) images of mild and severe cases of COVID-19. (a) On April 3, the first CT scan of patient 6 showed an isolated nodule outside the left lower lobe of the lung. On April 4, patient 6 received nebulization treatment. On April 10, the second CT examination showed that the density of the left inferior lobe nodule was significantly lower, with a narrow range. On April 21, the third CT examination showed that the lesions in the lower left lung were completely absorbed. The absorption time of similar lung lesions in another patient who did not receive nebulization of MSC exosomes was slower than that of patient6. (b) From February 27, the patient 2 received nebulization treatment. On March 18, the CT scan of patient 2 showed obvious absorption of lesions in both lungs, and the density of the lesions continued to fade. On April 1, the pulmonary lesions in patient 2 were absorbed completely. In the other patient who did not receive nebulization treatment, the presence of a fibrous cord shadow remained after absorption of the pulmonary focus. 

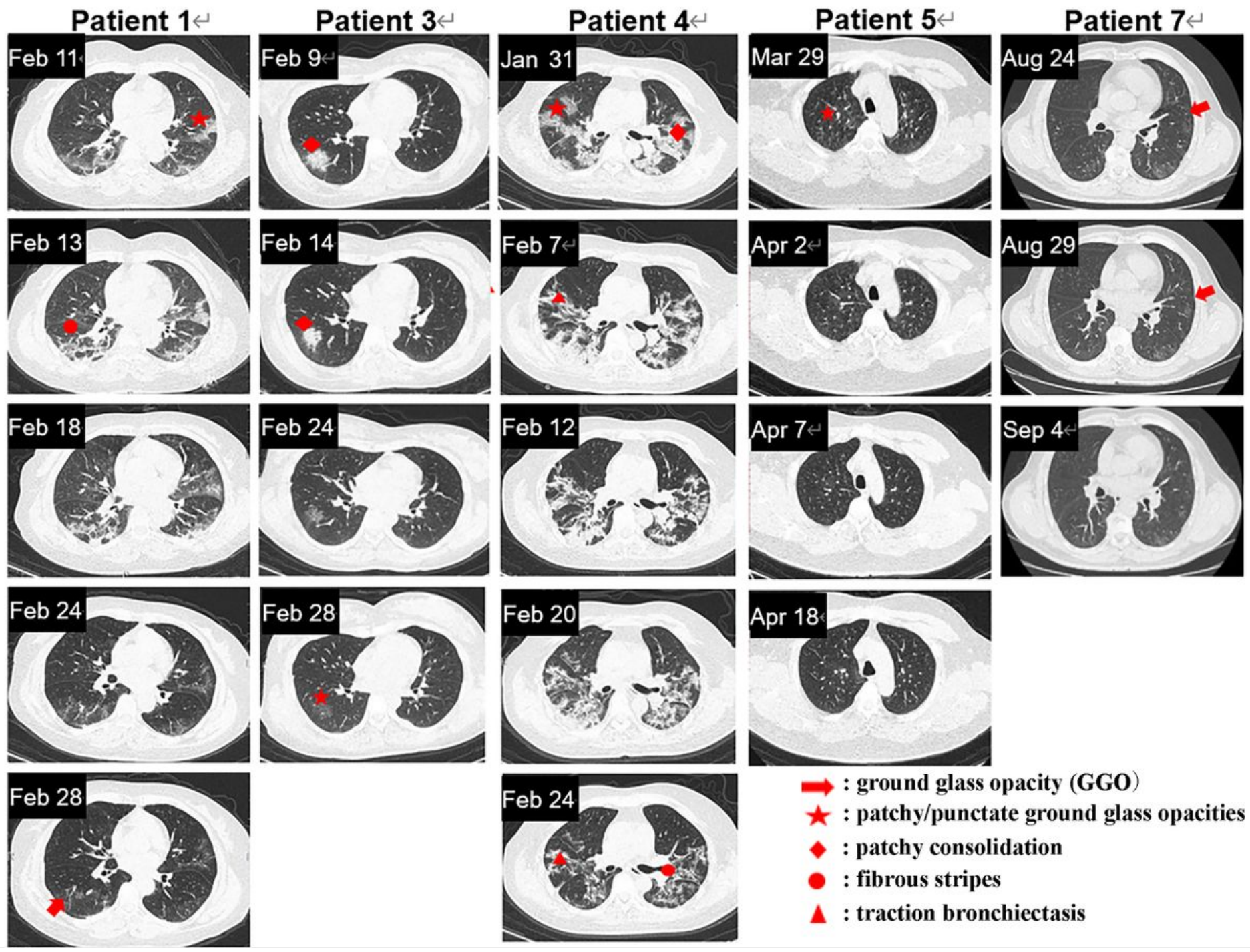

$\Rightarrow$ : ground glass opacity (GGO)

$\star$ : patchy/punctate ground glass opacities

: patchy consolidation

- : fibrous stripes

$\Delta$ : traction bronchiectasis

Figure 4

Chest computed tomography (CT) images of patients 1, 3, 4, 5 and 7. The nebulization treatment in patients 1,3 , and 4 started on February 27 . The nebulization treatment for patients 5 and 7 started on April 1 and August 20, respectively. 